\title{
DESAIN MODEL PRAKTIKUM IPA BERBASIS JAS (JELAJAH ALAM SEKITAR) DI SEKOLAH DASAR SE-KECAMATAN BENDOSARI
}

\author{
Dwi Anggraeni Siwi, Nurratri Kurnia Sari \& Koko Prasetya \\ PGSD FKIP Universitas Veteran Bangun Nusantara Sukoharjo \\ deanggraenny@yahoo.com
}

\begin{abstract}
The purpose of this study are 1) describe of the initial conditions of the practicum in a Primary School District of Bendosari to improve the understanding of the material and activate learners' understanding; 2) The design prototype model of lab-based science JAS applied in a Primary School District of Bendosari; 3) The final form of the model design lab-based science JAS applied in a Primary School District of Bendosari. This research is the development, conducted in sub-district elementary Bendosari Festive Year 2015/2016. In this research, the techniques were the development of needs analysis and design study model. The results in this study are the 1) Initial Condition form of characteristic learning model integrative who can not equip students in the control and learning science is: a model that contains the syntax: Mastery of the science material and mastery of practical science-based tracking the nature (JAS). 2) The initial design of models of labbased science tracking the nature (JAS) in the form of a syllabus, lesson plans, and worksheets. 3) In the vote on the model validator lab stated that lab model design based science used tracking the nature (JAS) can be used through the revision stage.

Keywords: Practicum, Natural Sciences, JAS (Roaming Neighborhood Nature)
\end{abstract}

\begin{abstract}
ABSTRAK
Tujuan dari penelitian ini adalah1)deskripsi kondisi awal kegiatan praktikum di Sekolah Dasar se- Kecamatan Bendosari untuk meningkatkan pemahaman materi, mengaktifkan peserta didik; 2)Desain prototype model praktikum IPA berbasis JAS yang diterapkan di Sekolah Dasar seKecamatan Bendosari; 3)Bentuk akhir desain model praktikum IPA berbasis JAS yang diterapkan di Sekolah Dasar se- Kecamatan Bendosari. Penelitian ini merupakan penelitian pengembangan, dilakukan di SD se-Kecamatan Bendosari Tahun Ajar 2015/2016. Dalam penelitian ini teknik pengembangan hanya pada analisis kebutuhan dan desain model pembelajaran. Hasil pada penelitian ini adalah adanya 1)Kondisi Awal berupa karakteristik model pembelajaran integratif yang dapat belum membekali siswa dalam penguasaan dan pembelajaran IPA adalah: model yang berisi sintaks: Penguasaan terhadap materi IPA, Kedua, penguasaan praktikum IPA berbasis Jelajah Alam Sekitar (JAS). 2)Desain awal model praktikum IPA berbasis Jelajah Alam Sekitar (JAS) berupa silabus, RPP, dan LKS. 3)Pada penilaian validator pada model praktikum menyatakan bahwa desain model praktikum IPA berbasis Jelajah Alam Sekitar (JAS) dapat digunakan melalui tahap revisi.
\end{abstract}

Kata Kunci : Praktikum, Ilmu Pengetahuan Alam, JAS (Jelajah Alam Sekitar) 
181 | Premiere Educandum, Volume 6 Nomor 2, Desember 2016, 180 - 188

\section{A. PENDAHULUAN}

Pelaksanaan pembelajaran IPA di SD se-Kecamatan Bendosari masih didominasi oleh suatu kondisi kelas yang masih terfokus pada guru sebagai sumber utama dari pengetahuan. Metode ceramah masih menjadi pilihan utama guru dalam mengajar, sedangkan proses praktikum belum biasa dikembangkan dalam proses pembelajaran. Aktivitas siswa dalam kegiatan belajar mengajar masih kurang, siswa hanya menerima pengetahuan yang berasal dari guru saja. Siswa masih minimal sekali melakukan kegiatan yang melibatkan keterampilan dan kemampuan berpikir, ketika pelaksanaan pelajaran guru masuk kelas memberikan materi secara ceramah yang kadang kala menggunakan bantuan media powerpoint. Proses pembelajaran yang monoton ini menyebabkan siswa menjadi pasif, tidak termotivasi dan minat terhadap pelajaran biologi rendah.

Pelaksanaan penelitian dalam pembelajaran IPA dilaksanakan melalui kegiatan praktikum. Kegiatan ini dapat menarik minat dan motivasi belajar siswa serta dapat membantu meningkatkan pemahaman pada materi yang di praktikumkan. Pada kompetensi dasar pembelajaran IPA di tingkat SD terdapat beberapa KD yang mengharuskan adanya kegiatan praktikum dalam pembelajaran. Hal ini menuntut guru IPA untuk mampu membimbing dan merencanakan kegiatan praktikum yang akan dilakukan, agar kegiatan tersebut dapat berjalan dengan lancar.

Ilmu Pengetahuan Alam (IPA) berkaitan dengan cara mencari tahu tentang alam secara sistematis, sehingga IPA bukan hanya penguasaan kumpulan pengetahuan yang berupa fakta-fakta, konsepkonsep, atau prinsip-prinsip saja tetapi juga merupakan suatu proses penemuan. Pendidikan IPA diharapkan dapat menjadi wahana bagi peserta didik untuk mempelajari diri sendiri dan alam sekitar, serta prospek pengembangan lebih lanjut dalam menerapkannya di dalam kehidupan sehari-hari. Proses pembelajarannya menekankan pada pemberian pengalaman langsung untuk mengembangkan kompetensi agar menjelajahi dan memahami alam 
Dwi Anggraeni Siwi, Nurratri Kurnia Sari \& Koko Prasetya: Desain ... |182

sekitar secara ilmiah. (Depdiknas, 2006; Sri Wuryastuti, 2008)

Pendekatan pembelajaran

Jelajah Alam Sekitar (JAS) adalah salah satu inovasi pendekatan pembelajaran IPA dan kajian ilmu lain yang bercirikan memanfaatkan lingkungan sekitar dan simulasinya sebagai sumber belajar melalui kerja ilmiah, serta diikuti pelaksanaan belajar yang berpusat pada siswa. Belajar adalah kegiatan aktif peserta didik dalam membangun pemahaman atau makna. Hal ini menunjukkan bahwa pendekatan pembelajaran JAS memberi keleluasaan kepada peserta didik untuk membangun gagasan yang muncul dan berkembang setelah pembelajaran berakhir. Di sisi lain dengan pendekatan pembelajaran JAS dapat menciptakan situasi yang mendorong prakarsa, motivasi dan tanggung jawab siswa untuk belajar sepanjang hayat. (Yuniastuti, 2013; Ridlo, Saiful, 2005)

Pembelajaran JAS dapat dilakukan dengan berbagai metode seperti tanya jawab, diskusi, demonstrasi, termasuk kegiatan praktikum. Inkuiri yang dilakukan dengan kegiatan laboratorium memposisikan seolah-olah peserta didik sebagai scientist yang melakukan suatu eksperimen dalam upaya mencari hubungan antar gejala alam. Akan tetapi apabila kegiatan ini dilakukan tanpa adanya tahapantahapan tertentu dapat dipastikan akan menemui kegagalan. Maka dalam pelaksanaannya perlu adanya bimbingan atau petunjuk untuk peserta didik.

Tujuan dari penelitian ini adalah untuk mengkaji 1) Keefektifan kondisi awal kegiatan praktikum di Sekolah Dasar se- Kecamatan Bendosari untuk meningkatkan pemahaman materi, mengaktifkan peserta didik; 2) Desain prototypemodel praktikum IPA berbasis JAS yang diterapkan di Sekolah Dasarse- Kecamatan Bendosari; 3) Bentuk akhir desain model praktikum IPA berbasis JAS yang diterapkan di Sekolah Dasar seKecamatan Bendosari.

\section{B. METODE PENELITIAN}

Model pengembangan yang digunakan dalam penelitian ini adalah Model Pengembangan Plomp (2001) yang menggunakan lima tahapan, yakni (1) preliminary investigation, 
183 | Premiere Educandum, Volume 6 Nomor 2, Desember 2016, 180 - 188

(2)

$$
\text { design, }
$$

realization/construction

(4) test,

evaluation, revision dan

implementation.

Analisis ini terdiri dari aktivitas data reduction, data display, dan conclusion drawing (Sugiyono, 2008). Tahapan dilanjutkan pada fase perancangan (design) sampai menghasilkan alternatif solusi yang berupa desain awal. Alur penelitian dapat digambarkan sebagai berikut

Potensi dan masalah di sekolah

1. Dalam pembelajaran belum diterakan praktikum di SD Bendosari

2. Siswa SD masih memerlukan banyak bimbingan dalam pelaksanaan pembelajaran.

3. Pembelajaran belum mengkaitakan pada Alam sekitar.

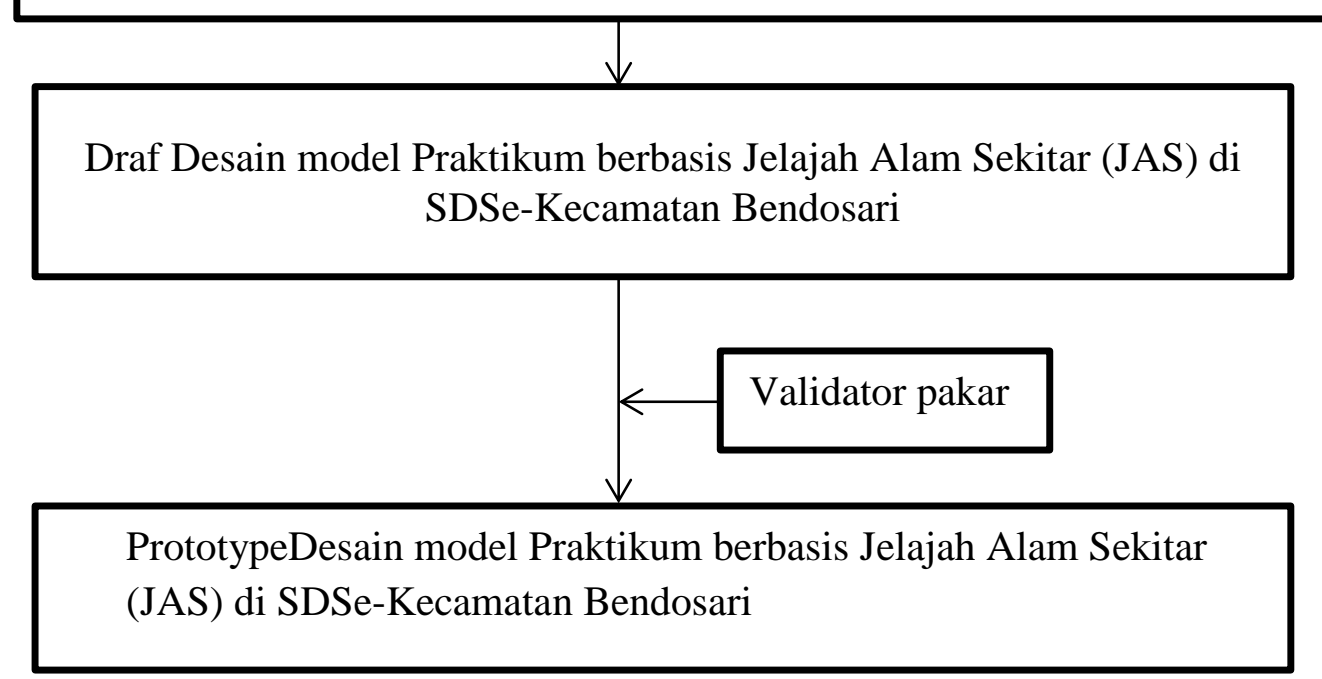

Gambar 1. Alur Penelitian

\section{HASIL PENELITIAN \& PEMBAHASAN \\ 1. Analisis Kebutuhan}

Berdasarkan hasil studi pendahuluan, maka terdapat dua hal yang menjadikebutuhan siswa agar kemampuan praktikum IPA dalam pembelajaran bermakna menjadilebih baik. Pertama, Siswa perlu menguasai cara kerja praktikum IPA,Kedua, penguasaan IPA mencakup pembelajaran Jelajah Alam Sekitar (JAS). Ketiga, Penguasaan terhadap mata pelajaran IPA.

a. Studi Pendahuluan pada SiswaSekoah Dasar se-

Kecamatan Bendosari

Sebelum dilakukan pengembangan perangkat perkuliahan, penelitian diawalidengan survai pendahuluan terkait dengan pandangan guru 
Dwi Anggraeni Siwi, Nurratri Kurnia Sari \& Koko Prasetya: Desain ... |184

terhadap pembelajaran Ilmu

Pengetahuan Alam (IPA),

penguasaan mahasiswa terhadap

bidang studi IPA, serta pandangan

siswa terhadapkemampuan dalam

memahami praktikum IPA. Survai juga dilakukan untukmemperoleh data sekunder, yakni bahan ajar yang diberikan siswa.

Hasil survei menunjukkan bahwa kemampuan siswa kelas 3 Sekolah Dasar Se-Kecamatan Bendosari dalammenguasai materimateri konsep dasar berbagai mata kuliah yang berisikankonsep dasar mata pelajaran IPA cukup memadai. Hal tersebut ditunjukkan darinilai mata pelajaran IPA yang diperoleh siswa SD sebagian besar bernilai minimal 67.

Survai juga dilakukan pada siswa SD se-Kecamatan Bendosari tentang pembelajaran IPA.Hasil survai menunjukkan bahwa setelah lulus dari perkuliahan Pembelajaran IPA, mahasiswa merasa masih belum mampu untuk mengintegrasikan matapelajaran dengan Alam Sekitar sehingga menghasilkan pembelajaran yang bermakna. Pembelajaran praktikum juga dikeluhkan oleh siswa
SD se-kecamatan Bendosari karena rencanasetelah pembelajaransiswa tidak diberi kesempatan yang luas untukmengeksplorasi lingkungan di sekitar sekolah dan rumah mengintegrasikan mata pelajaran. Selain itu,dominasi guru dalam pembelajaran sangat besar sehingga kemampuan siswa tidak berkembang. Siswa juga merasa belum memperoleh aplikasi IPA melalui praktikum yang berbasis JAS (Jelajah Alam Sekitar).

b. Studi Pendahuluan pada Guru Sekoah Dasar se-Kecamatan Bendosari

Studi pendahuluan juga dilakukan untuk melihat profil guru sekolah dasar se-Kecamatan Bedosari berkaitan dengan kemampuan menyusunpembelajaran praktikum IPA, kemampuan keterampilan proses dan penilaian autentik.Hasil survai menunjukkan bahwa sebagian guru-guru sekolah dasar sekecamatan Bendosari kurang dalam kemampuan menyusun pembelajaran praktikum, terutama dalammengintegrasikan mata pelajaran, kurang dalam melakukan keterampilan proses praktikum IPA. 
185 | Premiere Educandum, Volume 6 Nomor 2, Desember 2016, 180 - 188

Survai juga dilakukan

berbagai pendekatan, strategi, metode

untukmemperoleh data sekunder, danteknik pembelajaran yang yakni dokumen SKGK (Standar Kompetensi Guru Kelas), bahan ajar Kurikulum KTSP, dan dokumen Kurikulum KTSP.

Berdasarkan kebutuhan mendidik secara kreatif dalam mata pelajaran IPA, dan menerapkan pembelajaran praktikum IPA khususnya di kelas 3 SD seKecamatan Bendosari.

tersebut maka disusunlah sebuah model yang dapatmenampung kebutuhan siswa tersebut. Model tersebut kemudiandiimplementasikan dalam pembelajaran IPA. Perangkat perkuliahan kemudiandikembangkan berdasarkan model tersebut.

\section{Desain perangkat perkuliahan}

Spesifikasi produk yang akan dihasilkan adalah Silabus, Rencana PelaksanaanPembelajaran, bahan ajar dan Lembar Kerja Siswa.

a. Penentuan kompetensi dasar

Menurut Standar Kompetensi Guru Kelas, seorang guru kelas harus mampumenguasai teori belajar dan prinsip-prinsip pembelajaran yang mendidik. Adapunindikator dari standar kompetensi tersebut adalah mamapu memahami berbagai teori belajar dan prinsip-prinsip pembelajaran yang mendidik terkait dengan mata pelajaran IPA di SD seKecamatan Bendosari, menerapkan

b. Penentuan indikator

Indikator yang dimaksudkan dalam perangkat perkuliahan ini adalah indikator dari kompetensi dasar. Adapun indikator dari kompetensi dasar yang dimaksud adalah:

1) Menyusun praktikum berbasis Jelajah Alam Sekitar (JAS) meliputi mengidentikfikasi ciriciri mahkluk hidup dan kebutuhan mahkluk hidup.

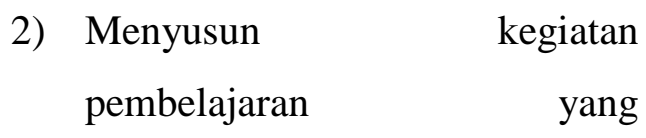
mendeskripsikan keterampilan proses danpengetahuan yang merupakan hasil suatu proses.

3) Menyusun rencana pelaksanaan pembelajaran praktikum berbasis Jelajah Alam Sekitar (JAS) menggunakan tema alam sekitar sekolah.

c. Penentuan tujuan pembelajaran 
Dwi Anggraeni Siwi, Nurratri Kurnia Sari \& Koko Prasetya: Desain ... |186

Berdasarkan indikator yang telah tersusun, maka dijabarkanlah beberapa tujuan pembelajaran dari perangkat yang dikembangkan. Adapun tujuan dari pembelajaran dalam perangkat pembelajaran ini adalah sebagai berikut,

1) Siswa mengamati makhluk hidup(baik tumbuhan, hewan dan manusia) di lingkungan sekitar.

2) Siswa menyebutkan ciri-ciri makhluk hidup dan benda mati berdasarkan pengamatan langsung.

3) Siswa menyebutkan contoh makhluk hidup dan makhluk tak hidup yang dijumpai di lingkungan sekitar.

4) Setelah siswa mendiskusikan kebutuhan makhluk hidup diharapkan siswa menjelaskan cara pemeliharaan tumbuhan (panca usaha tani).

5) Siswa menyebutkan pertumbuhan hewan dari pengamatan gambar.

6) Siswa menjelaskan pertumbuhan atau perubahan ukuran tumbuhan melaluipengamatan/gambar.

7) Siswa menjelaskan perkembangan dan perubahan tubuh manusia melalui pengamatan langsung atau gambar.

d. Penyusunan bahan ajar

Bahan ajar disusun sebagai panduan dan alat bantu siswa dalam menerima materi. Bahan ajar berisi dasar-dasar teori apabila seseorang hendakmenyusun RPP untuk Kurikulum KTSP sekaligus pedoman praktisnya.

e. Penyusunan Lembar Kerja Siswa Lembar kerja mahasiswa disusun untuk digunakan sebagai panduan bagi siswa untuk melakukan praktikum IPA berbasis JAS (Jelajah Alam Sekitar). Selain itu LKS juga digunakan sebagai panduan dalam mengaplikasikan praktikum dalam pembelajaran kelas 3 SD seKecamatan Bendosari.

\section{Bentukakhir prototipe model praktikum IPA berbasis JAS}

Validasi dari ahli yang bergelar Magister di bidang mata pelajaran IPA, kurikulum SD, dan desain bahan ajar dilakukansebelum dilakukan uji coba perseorangan. Beberapa masukan yang diperoleh pada saat proses. 
187 | Premiere Educandum, Volume 6 Nomor 2, Desember 2016, 180 - 188

\section{SIMPULAN}

Berdasarkan hasil penelitian maka dapat disimpulkan,

1. Kondisi Awal berupa karakteristik model pembelajaran integratif yang dapat belum membekali siswa dalam penguasaan dan pembelajaran IPA adalah: model yang berisi sintaks: Pertama, Penguasaan terhadap materi IPA, Kedua, penguasaan praktikum IPA berbasis Jelajah Alam Sekitar (JAS).

2. Desain awal model praktikum IPA berbasis Jelajah Alam Sekitar (JAS) berupa silabus, RPP, dan LKS.

3. Pada penilaian validator pada model praktikum menyatakan bahwa desain model praktikum IPA berbasis Jelajah Alam Sekitar (JAS) dapat digunakan melalui tahap revisi.

\section{DAFTAR RUJUKAN}

Depdiknas. 2004. Pedoman khusus pengembangan silabus berbasis kompetensi SMP mata pelajaran Pengetahuan Alam. Jakarta: Depdiknas.

Dimyati dan Mudjiono. 2002. Belajar dan Pembelajaran. Jakarta : Rineka Cipta.
Marianti, A dan N/E. Kartijono. 2005. Jelajah Alam Sekitar (JAS) Dipresentasikan pada Seminar dan Lokakarya Pengembangan Kurikulum dan Desain Inovasi Pembelajaran. Semarang : Jurusan Biologi FMIPA UNNES

Mulyani, Sri.E.S. 2008. Jelajah Alam Sekitar (JAS) Pendekatan Pembelajaran Biologi. Semarang : Jurusan Biologi FMIPA UNNES

Ridlo.S, 2005. Pendekatan Jelajah Alam Sekitar (JAS) Dipresentasikan pada Seminar dan Lokakarya Pengembangan Kurikulum dan Desain Inovasi Pembelajaran. Semarang : Jurusan Biologi FMIPA UNNES

Sri Sulistyorini. 2007. Model pembelajaran IPA sekolah dasar dan penerapannya dalam KTSP. FIP PGSD Universitas Negeri Semarang.

Sri Wuryastuti. 2008. Inovasi pembelajaran IPA di sekolah dasar. JURNAL Pendidikan Dasar. Nomor: 9 - April 2008

Sumaji, dkk. 1998. Pendidikan sains yang humanistis. Yogyakarta: Penerbit kanisius.

Trianto. 2007. Model pembelajaran terpadu dalam teori dan praktek. Jakarta: Prestasi Pustaka.

Yuniastuti. 2013. Upaya Meningkatkan Keterampilan Proses dan Hasil Belajar 
Dwi Anggraeni Siwi, Nurratri Kurnia Sari \& Koko Prasetya: Desain ... |188

Biologi dengan Pendekatan

Pembelajaran Jelajah Alam

Sekitar pada Siswa Kelas VII

SMP Kartika V-1 Balikpapan.

Jurnal Ilmu-Ilmu Sosial. 5: 31-

38

Uno, Hamzah B \& Nurdin Mohammad. 2011. Belajar dengan Pendekatan Pailkem.

Jakarta: Bumi Aksara.

Ridlo, Saiful. Pendekatan Jelajah Alam Sekitar. Makalah seminar. Disampaikan dalam Semlok Pengembangan kurikulum dan Desain Inovasi Pembelajaran Biologi Program Setudi Pendidikan Biologi dengan Pendekatan JAS tanggal 14-15 dan 22-23 Februari 2005. Semarang : Jurusan Biologi FMIPA UNNES.2005 